\title{
Kasurupan: Spirits Taxonomies and Interpretation in the Practice of Kasenian Réak
}

\author{
Luigi Monteanni \\ University of Bologna, Italy \\ e-mail: monteannilu@gmail.com
}

Published online: 25 December 2020

Cite this article (APA): Monteanni, L. (2020). Kasurupan: Spirits taxonomies and interpretation in the practice of kasenian Réak. Jurai Sembah, 1(2), 27-35. https://doi.org/10.37134/juraisembah.vol1.2.3.2020

\begin{abstract}
Kasenian réak is a regional variant of the Javanese horse dances from Bandung, Indonesia. Commonly known in the archipelago as jaranan, kuda lumping or jathilan, the Javanese horse dances are a group of ceremonial musical performances during which a group of performers, led by a trance master, undergo voluntary possessions on behalf of spirits of the ancestors and other supernatural beings, under the influence of a musical ensemble. In different possession and trance phenomena around the world recognizing the acting spirit is often the key to communication with the supernatural being and treatment of the possessed. Thus, more or less different and precise taxonomies may be developed in order to do so. In réak, the possessed behaviour is interpreted by the trance master and members of the group in order to meet the spirit's various demands and act accordingly to manage the possession. The purpose of this article is to examine the spirits' taxonomies at play in réak as a case study. I do this in order to show in which sense analyses of the phenomenon of possession based on classification often fail to grasp the complexity and thus the significance of the experience. The outcome will underline which benefits can be obtained by a an approach that gives more value to a context-based ethnography of the possessed and its peculiarities than to the development of a general theory of possession with comparative purposes.
\end{abstract}

Keywords: Possession, performance, supernatural beings, taxonomies, West-Java

\section{Introduction}

When we talk about spirit possession in the common sense, we usually employ the term in a way that does not take into account the different cultural specificities and taxonomies of the experience. Rather, thanks to countless literary accounts and their various renditions in popular, mass culture, the term is used in a way that brings together radically different beliefs and interpretations of altered states of consciousness, ideas of self and identity and, of course, other-worldly beings (Cohen, 2008). Beyond what may seem a merely linguistic issue, such a narrow and generic understanding of possession may even prejudice the validity and legitimacy of any in-depth inquiry on the phenomenon, implying many logical and theoretical biases that such an employment may generate.

The latin word itself from which the term derives (possidere), shows how the Christian, catholic perception of the phenomenon as an undesirable state of consciousness caused by a nefarious supernatural being has shaped the concept in a very cultural-specific interpretation shared by the majority of the global North (Beneduce, 2002). Specularly, many regional cultures don't have a generic term to address possession, usually preferring ethno-specific expressions which describe the experience more accurately (Azzaroni, 1994). But what do we really talk about when we talk about spirit possession?

Academic anthropological studies on the subject agree that spirit possession "commonly refers to the hold exerted over a human being by external forces or entities more powerful than she is" (Boddy, 1994, p. 407). According to Bourguignon, possessions can be divided into two forms: "One form of possession causes a change in bodily functioning; the other form of possession alters consciousness, awareness, the 
personality or will of the individual" (1976, p. 3). More specifically, following Cohen's definition (2008, p. 3), we refer to these two forms of possession as pathogenic and executive.

Pathogenic possession concepts result from the operation of cognitive tools that deal with the representation of contamination (both positive and negative); the presence of the spirit entity is typically (but not always) manifested in the form of illness. Executive possession concepts mobilise cognitive tools that deal with the world of intentional agents; the spirit entity is typically represented as taking over the host's executive control, or replacing the host's 'mind' (or intentional agency), thus assuming control of bodily behaviours.

In this sense, addressing and analyzing the phenomenon of possession nowadays means taking into account not only its generally admitted features, but most importantly the lived experience of the people involved in the phenomenon as the only accurate gateway to a more precise understanding. This paradigm which goes toward an ethnography of the possessed has precisely two advantages: first it deconstructs the presumed conceptual unity of the possession as a purely theoretical construct and second it underlines that taxonomic biases can often be present also in indigenous classifications.

\section{Methodology}

In this paper, drawing extensively from ethnographic data gathered during my 2017 fieldwork in Bandung and existing literature on the subject, I will analyze réak's peculiar possession taxonomies and experiences as a case study. I do this in order to stress two points. First, that possession is a composite category that brings together extremely heterogeneous experiences. Second, that theoretical classifications of the phenomenon, both cross-cultural and regional, can oversimplify an experience whose meaning is seldom fixed and constantly negotiated by the interplaying actors.

The article is based on thirty interviews conducted in Bahasa Indonesia and Basa Sunda by the author with the help of Teguh Permana and Gigi Priadji. Interviews have been made with réak performers and musicians from different groups, but also of aficionados and amateurs. The interviewees were selected on the basis of their different roles (leaders, trance masters, musicians, assistants) ages (approximately eighteen to eighty years old) and gender (with a predominance of male interviewees). Interviews have been collected in 2017, from December to March, in more or less informal context chosen by the interviewees: mainly their houses, rehearsal rooms, the schools and universities they were attending and local bars and coffee-shops. Every interview lasted at least one hour up to two hours.

In the first part of the article I am going to give a brief account on the structure and role of kasenian réak for the Sundanese communities in the Bandung regency. In the second part I will briefly reconstruct the history of the style as a subgenre of the Javanese horse trance dances (jaranan). Finally, in the third and fourth part I will analyze réak's taxonomies of the possession experience and their controversies in order to underline how a deeper understanding of the phenomenon may be found only outside its theoretical assessments.

\section{A Brief Outline of Kasenian Réak}

Kasenian réak (literally the 'réak art') is a Sundanese ceremonial performance practiced throughout the regency of Bandung, a province located in West-Java, Indonesia. Now approximately one hundred years old, it is mostly organized to celebrate fundamental milestones and rites of passage of the Sundanese Muslim life cycle (hajatan) such as circumcisions and weddings. Nonetheless, the performance is more and more displayed also in secular contexts such as political and educational institutions, cultural and artistic festivals and even contests. It consists in an eight hours event where a trance master and spirit medium called ma 'alim coordinates a series of voluntary possessions of both audience members and performers under the influence of a musical ensemble.

Each réak group is composed of fifteen to thirty persons with different roles within an almost fixed hierarchy. This hierarchy is divided, in order, between leader, or pimpinan, founder and guide of the group, one or two ma'alim, musicians and helpers. The musical section is composed of a set of four single-head conical drums named dogdog, a large barrel-shaped drum called bedug, a double reed wind instrument called tarompet and a kecrek, a stack of iron plates hit with a wooden hammer. While she is not a formally required part of the ensemble, a female singer (sinden) is often present. Even though such performance is believed to be most suitable for men and if it's true that male practitioners are the large majority, participants 
have often asserted that réak is not a prerogative of men. I have personally seen women taking part in the show playing various roles, albeit being a minority and few exclusively female réak groups being known.

While the average repertoire features almost only Sundanese regional songs common to many styles of Sundanese traditional music, younger, more recent ensembles have shown the progressive tendency to experiment with many different contemporary popular genres, including pop Sunda, dangdut, rock and even metal and punk (Monteanni, 2020). Groups are paid to perform by the party's host and depending on the group they may even be quite expensive. Nevertheless, earnings are never a sufficient income. Thus, réak is a secondary activity for the great majority of people who practice it, who are usually blue-collar workers of humble origins.

During the trances, individuals are either possessed by spirits of their ancestors (Karuhun) or by spirits of the supernatural world (alam gaib) believed to inhabit unclean spots of the urban environment (toilets, backyards, trash) (Kasmana et al., 2018) as well as particular spots of the natural landscape such as mountains and forests (jurig jarian) (Rapoport, 2018). Jurig jarian can be of various types: otter, horse, buffalo, snake, tiger, monkey and even the Buta (ogre). While the former are considered to be polite spirits kind in nature, the latter are regarded as chaotic, terrifying and even funny. Interviewees describe the particular atmosphere of réak as a multi-sensorial mixture of terror (takut), tangled, busy noisiness (ramé) and grotesque, trivial humour (bodor). Réak is, following Geertz's taxonomy of performing arts (1976), thus classified as a kasar (unrefined/coarse) performing art, in opposition to elegant, alus (refined) types of entertainment and performances such as Wayang Kulit or tarawangsa.

Besides the adorcistic practice led by the ma'alim. Members of the group and audience can also be possessed by the entities with no previous notice. This usually happens due to a certain predisposition of the person to the invisible forces. This tendency can be determined both by physical and psychological strength or weakness of the person and the corresponding choice of a specific individual by the spirit. Involuntary possessions often happen when an exorcised spirit 'jumps' into another body, albeit not only under these circumstances.

Even if the possessed are imbued with superhuman power which at least theoretically prevents their bodies to be harmed by their extreme actions, it is a ma'alim's responsibility to ensure that the performance is always under control. He has to ascertain, as we will see later, that each body is hosting the most suitable spirit, that each possession is starting and finishing at the right time - i.e. that adorcisms and exorcisms are enacted correctly and at the right moment - that the spirits' requests are satisfied and obviously that no one is getting hurt during the performance. Even before the beginning of the performance is a ma 'alim's primary duty to carefully prepare the offerings to the spirits (sasajen or pangradinan) and ask for their permission to stage the show, while inviting them to participate (roh diundang).

Possessions are generally believed to be the most delicate and interesting element of the whole event, although the spectacular stunts of jurig jarian are regarded as the apex of performative entertainment. Nevertheless, to the formal development and positive outcome of the performance, its musical and supernatural components are equally crucial, as they both contribute to the entertainment (hiburan) and to successfully create the right environment for the spirits.

\section{From Jaranan to Kasenian Réak}

Kasenian réak is a quite recent regional variant of the Javanese horse trance dances. The horse trance dances are a group of performances allegedly originated in East-Java that eventually spread on and even abroad, brought to Singapore, Philippines, Surinam, Malaysia and Australia by Javanese immigrants (Rapoport, 2018). Regional variants of the phenomenon are known with different names, the most common being jaranan, jathilan, kuda kepang, reog and kuda lumping.

In the common structure of the performance, as described by Mauricio (2002), entranced performers dance while brandishing hunting weapons and 'riding' flat hobby horses under the influence of real or pretended possessions on behalf of ancestral or rural spirits. The centrality of the figure of the horse could be speculatively linked to the Javanese symbolism of the animal, perceived as a creature completely yielding its will to the rider, representing the way dancers should submit themselves to the spirits (ivi, p. 23). Alternatively, as we will see later, this could have been determined by the importance of the animal in relation to military (Kartomi, 1976), logistic and hunting purposes (Mauricio, 2002).

According to the most authoritative historical reconstructions, the exact origins of the horse dances are unknown (ivi). Much of the literature certainly agrees in placing it within animist Java (Christensen, 2014). To be more precise, it is likely that jaranan was already practiced before the adoption of Hinduism 
(around the 6th or 7th century) (Kartomi, 1973). According to the Javanese tradition, reog has emerged in the fourteenth century. If anything, this would entail the existence of the horse dances from at least the previous century. The focus on the figure of the horse also tells us that the performance had to have originated after the animal had already been introduced to the archipelago. The event, generally dated around $800 \mathrm{AD}$, according to Mauricio, could go back to much earlier (around $300 \mathrm{BC}$ ) thanks to an earlier introduction of the animal to Java by Chinese merchants (2002).

The origin and development of jaranan are generally linked to the hunting liturgy. Among the rituals of the hunter-gatherers, dances ending up in a trance were staged in which the movements of different animals were emulated in order to seek their protection or gain their energy to have a successful hunt (ivi). From another perspective it could instead have had a strictly military origin. Kartomi (1976) underlined how the performance could have been born as a demonstration of military prowess on horseback, or alternatively as a subsequent imitation of these demonstrations by adults and children, being later associated with magic-religious elements connected to fertility and eroticism, trance states and animal symbolism.

Pigeaud has stated that jaranan probably spread to West Java from Cirebon (Van Groenendael. 2008), while Kartomi has shown how during the seventies it was already practiced in Indramayu (1976). According to ethnographic data I have gathered, réak as a distinct genre has originated during the thirties in the Bandung regency as seni lungsuran, a term indicating a group of art forms that are not originally of the area in which they are practiced, but adapted from elsewhere (Monteanni, 2020).

Since the sixties, réak has seen a steady but continuous growth in popularity. From its two founding groups, Juarta Putra and Maska Putra, in 2017 numbers had grown to more than 200 in the Bandung area alone. On a national level, this is an effect of the administration and development of Indonesian cultural policies after Indonesia's independence, the reconstruction of which goes beyond the scope of this article. Nonetheless we can mention how since 1998, with the end of Suharto's New Order and the new legislation on regional autonomy, after more than thirty years of authoritarian rule, a process of return to regional cultures began, towards policies in defence of cultural differentiation and a reaction to national hegemony.

On a local level, the introduction of public address systems (toa), sinden and tarompet in the nineties played a vital role in réak's rise in popularity. This is particularly true for younger generations, who often describe it as a very urban and raw performance, which extremifies the 'metal' drift of some of the Sundanese traditional performing arts. Nowadays, youngsters especially see the performance as a way to revitalize Sundanese culture, gaining individual agency and social capital. This does not come without some complications with elder groups and practitioners, related to negotiations of orthopraxis, normative behaviour and authenticity of the practice (Monteanni, 2020).

After almost one hundred years, réak is undergoing a process of strongly centralized bureaucratic and political legitimization posing related issues of "touristification" (Acciaioli, 2016). Since a couple years, the city of Bandung has begun to organize a census of all réak groups from the area, releasing certifications to attest their presumed authenticity. This latest process has seen many groups invited to participate and perform at secular, cultural events such as universities' anniversaries and political parties' celebrations and political campaigns, paradoxically cutting off older and even founder groups coming from the nexus of the style. In 2018 the first official réak contest was organized by the city of Bandung with the sponsor of 'Beautiful Indonesia', which, following this new bureaucratisation, has left out all groups outside the metropolis.

\section{Susurupan, Nyurup and Kasurupan}

To use the term possession to refer to all the phenomena of trance and altered states of consciousness that can be experienced during réak would be misleading, as only some of them are addressed as actual, proper possessions by other-worldly beings. All the experiences of altered states of consciousness can be in fact divided into three different types: susurupan, nyurup, kasurupan.

Susurupan or kerurupan is a term indicating a fake possession. In fact not all possessions are considered real. Although no one doubts that possessions are generally real, my interlocutors have often asserted that thirty to fifty percent of the cases are pretended. Reasons that may induce some individuals to fake a possession are: one's desire to freely flaunt his strength through certain behaviours which are normally believed to be socially unacceptable, one's poor emotional management which gives the belief of being possessed and, last, a psychophysical state altered by the illicit consumption of alcohol.

Nyurup (or surup) is a term used to indicate the harmony between a musician and his instrument or between a musician and the music. It characterizes a state in which the instrumentalist managed to "put his 
heart and soul inside the instrument.' This definition, which may seem merely figurative, actually designates a desired, proper trance (dedi) condition. This must be sought by the musician to gain the almost superhuman ability to continue playing for a few hours without experiencing pain or tiredness, thus allowing a successful execution. It is described as a feeling of supernatural energy obtained by entering into unity with the spirit of an ancestor (Karuhun). During this trance state, the performer feels that he does not have complete control over his movements and, therefore, that he cannot fully attribute to himself the musical execution. at the same time he is always conscious, managing to clearly remember everything that happens to him. This state of trance, although does not involve any proper possession by a spirit. This union can be experienced in various degrees: akur, the fusion between body and spirit, luyu, that is the fusion between emotions and spirit and sauyunan, or complete unity between one's spirit and his ancestor.

One can also speak of nyurup when the ma'alim manages to fit each spirit in the appropriate body during a possession. The reason for using the same term for two such different contexts is that in both of them it designates a unity intended as harmony between the parts. While the correct choice of the ma'alim - the right combination of body and spirit - can be called nyurup for both ancestors and jurig jarians, from the point of view of the possessed, only a possession on behalf of a Karuhun can be properly defined nyurup, since it is absolutely controlled and not chaotic.

Last, Kasurupan (also kaasupan or kaancinan) is the term used to describe proper possession. Namely, it is an altered state of consciousness during which an individual is taken over and possessed by a spirit. The individual finds himself unconscious throughout the course of the possession until the entity that was in control 'returns home' (pulang). The individual won't remember any of his actions, performed at least de jure by the spirit.

Another variant of kasurupan is the one described by Anggi Nugraha, member of group Juarta Putra, as nyarap. This second type of possession differs from the first in that the possessed, in spite of not being able to control its own actions, still manages to observe his own behaviour as a spectator from outside his body. Unable to react, he remains passive towards the entity.

During kasurupan the body can be possessed by a spirit that 'comes from the outside to the inside' (ti luar ka jero), entering from either of an individual's orifices, or on the contrary by one that 'comes from the inside to the outside' (ti jero ka luar). The first case is that of the jurig jarian, who are literally taken by the ma'alim and placed inside the body of the individual. In the second case, an Ancestor, a Karuhun will take control of the body from the inside.

First, when taking control of a body, different spirits will behave in different ways, thus allowing the audience to try and tell which spirit is in control of the body. Typically, Karuhun will display their knowledge and power delivering special messages to their relatives or dancing and exhibiting their pencak silat prowess. Jurig jarian, on the other hand, are known for boastfully showing off their superhuman abilities and resistance through stunts common to many horse dances (Mauricio, 2002; Van Groenendael, 2009; Rapoport, 2018). These practices include eating burning coals and sharp glass or breaking bricks and coconuts with their heads.

Second, other elements that allow onlookers to recognize the spirits are to be found in the entity's predilection towards some peculiar objects and foods included in the offerings and songs of their preference. The ritual offering, the sasajen, contains a series of objects of both material and symbolic value to the spirits. It includes, but depending on the group may be not limited to, rice crackers, sweet and black coffee, tea with and without sugar, water, cigars and cigarettes, bananas, a kujang, a cup containing an egg, uncooked rice, coins, small bottles of perfume. Either openly demanding for them or using a complex system of codified sign language, the spirits ask for specific items, foods and goods to consume. These are demands that have to be met mandatorily in order to please the entities. While the Karuhun prefer food or objects for human use, such as tea, coffee and cigarettes, kujang and iket, jurig jarian, on the other hand, are prone for raw meat, uncooked singkong leaves and other similar normally inedible items associated with an animal diet.

Third and last, a proper reading of the exorcistic practice is the clearest way to distinguish between a possession on behalf of a jurig jarian or a Karuhun. In the first case the ma'alim puts one of his hands on the neck of the possessed and the opposite arm around it, while uttering secret ajian-ajian. When the process is complete, the exorcised person falls into a paralysis from which the ma 'alim together with some assistants from the group 'unlock' him by seating the person on the ground, bringing his hands to his face. Simultaneously, the ma'alim and its helpers pass their hands over the head, arms, belly, chest, back and legs of the exorcised as if to shake something off him. These gestures are used to cleanse the body of what's left 
of the spirit, in order to be sure that the exorcism is successfully completed. After this process the individual slowly returns to consciousness, visibly exhausted.

In a second variant for jurig jarians, two of the group members crouch on the ground between the ma'alim and possessed. Holding hands, they stretch their arms forming a circular shape. The ma'alim then invites the spirit to jump across the circle and thus 'return home.' The possessed jumps towards the outstretched arms of the two assistants, twisting his whole body. Once he has reached the arms of the helpers he instantly falls into a paralysis. The ma'alim and the two helpers then hold him while he falls to the ground. Afterwards, the process continues identically to the first case.

It should be added that during the exorcistic process, jurig jarian usually oppose to the commands of the ma'alim refusing to leave the body. When the spirit shows a particularly strenuous and problematic resistance, a third exorcistic practice is that of ngabura. The ma'alim collects water in his mouth from a common glass or bottle, spitting it on the possessed. This process causes the immediate exit of the spirits, resulting in a paralysis and then following the aforementioned procedure.

As for the exorcism for the Karuhun, the process works through the employment of a medium. The mediums in question are objects belonging to the Karuhun or members of their family. After the polite request to leave the body on behalf of the ma'alim or the Karuhun himself, the objects or person are leaned against the forehead of the possessed person, who, upon contact, falls paralyzed to the ground.

\section{Classification as Negotiation}

We can see that the choice of either a determinate set of items from the sasajen or songs from the repertoire, the possessed bodily movements, behaviours and the practices of the ma'alim can help in approximately addressing both the nature of the presumed trance and the nature of a spirit, its belonging to either of the two categories (Karuhun or jurig jarian). Though, what appears theoretically to be a quite simple classification is not always that clear in the practice. As we are going to see, in fact, much of the judgement about the nature of the spirit is determined by a subtle negotiation between the possessed-spirit, the ma'alim and the audience. I will explain this more in detail after having taken into account three frequent exceptions which complicate the aforementioned classification.

First, additionally the Karuhun can display animal behaviours when they are 'in unity with an animal.' This happens when the ancestor is united with his kukutan. Literally translated by my interviewees as 'pet' or 'guardian spirit,' the kukutan was defined by my interlocutors as a specific spirit familiar that each of us has within him. Second, a spirit can leave the body of the possessed and be replaced by a different one without any need for an exorcism. This will happen when a wandering spirit notices that another has left a body before it is time, taking control of the individual before his actual soul can return to the body. A body cannot in fact host two spirits simultaneously, therefore a sudden change in the behaviour of the possessed is interpreted as a change of the spirit within it. Third, a pretended possession, susurupan, can create the conditions for a real one. An individual retaining disruptive and hostile feelings, or under the effects of alcohol and psychotropic substances creates the perfect physical conditions for a possession on behalf of jurig jarian. In general, we can also notice how the possessed often display contradicting behaviour, as Yudha of group Putra Jaya Melati has asserted; For example, when someone is possessed by the spirit of the horse $(k u d a)$ and the person climbs a tree, questions will arise. How can you climb a tree if a horse can't do it?

Thanks to these borderline cases, we can understand that beyond an approximate classification based on the decoding of the possessed behaviour, complete certainty is never given. A concrete proof of this is that, although my interlocutors have always shown some confidence in making distinctions and identifying entities during the course of a possession, at the request of further clarifications on what helped them to judge without a doubt, many replied that "only the ma'alim knows for sure."

We have mentioned that the ma'alim holds the responsibility of making sure that the performance is developing smoothly, according to its orthopractic principles. In particular, he has to make certain that each spirit is hosted by the most suitable body just like 'the appropriate case for a dagger.' This comes from the belief, shared around West Java (Foley, 1990), that the body is like a vessel, 'filled' by the soul or, in case of possession, a spirit. Despite the protection provided by the spirits, possession is generally regarded as an individually undesirable event, as it is capable of 'breaking the positive aura' (merusak aura positif), making people too susceptible to invisible energies. For this reason, voluntary adherence to the adorcistic practice is tendentially reserved to a certain type of individuals, able to physically, psychologically and 
spiritually stand the experience, bearing its consequences. These may vary from simple bruises and injuries up to literal madness.

Individuals with weak bodies and minds are susceptible to physical and psychological damage when possessed by a spirit too powerful, while an exceptionally strong individual might put in danger other people if the spirit he hosts is also especially powerful. Last, being 'unclean' - i.e. abstention from ritual prescriptions and consumption of alcohol and psychotropic substances - prevents the possibility of being possessed by a Karuhun, putting the person at the mercy of especially chaotic jurig jarian. We have in fact also mentioned how not all possessions are coordinated and decided by the ma'alim and are determined by the structural predisposition of an individual and his body.

In general, after showing the regional possession phenomena and supernatural entities taxonomy at play in kasenian réak, we can underline that beyond this very classification many elements make the reading of possession problematic and ambiguous. Indeed, we can see that, even if the spirit expresses and thus communicates recognizable traits of its nature, (1) Karuhun and jurig jarian share common, overlapping traits and behaviours, (2) spirits of different nature can take over the same body one after another; an occurrence that can be only noticed by a sudden change in the possessed behaviour. Moreover as we have shown (3) also a fake possession can become real and more in general (4) possessed people may show contradicting behaviours. Last, even if in principle the ma'alim 'couples' a body with a suitable spirit, (5) in no situation he controls the beginning of every single occurring possession.

In réak, differently from Christian (Talamonti, 2005) and Haitian (Deren, 1953) possessions, the spirits do not often explicitly reveal their identity and nature. As we have mentioned, possession is generally read through a supposed correspondence between the actions of both possessed and ma'alim and the beliefs that describe the nature and attitude of the spirits. Possession is in this case a fairly open exegetical issue. The only authority, the only one that can tell this for sure, thanks to the special relationship he has developed with the invisible, is of course the ma'alim. Only his actions and his interpretation can give an indisputable answer since the possessed cannot usually recall or reconstruct what happened during the possession or which spirit or spirits have taken control of him. Moreover, This answer is given only at the end of the possession, when the exorcistic practice finally occurs, revealing once and for all which kind of spirit was 'sent home.'

Nonetheless, two things are worth notice. First, possession and its treatment in réak are exquisitely relational. The public identity of the spirit is slowly revealed by an interplay between the requests and actions of the spirit on one side and the reactions of the ma'alim and group on the other. Second, during the performance, the audience comments and discusses the spirits possessing the bodies, trying to establish if they are Karuhun or jurig jarian. Moreover the ma'alim never explicitly expresses the nature of the spirit. In general, an accurate reading of the particular possession is not an element of utter interest for the audience. At least not as much as it is for the group and ma'alim, for whom it is a matter of practical necessity.

As I have tried to show elsewhere (Monteanni, 2018), this suspension and ambiguity of the phenomenon of possession in réak is precisely one of the elements that allows a social, public discourse on what it means to be human and what it entails on a social level. This gains particular relevance when we consider that circumcisions and weddings are both rites of passage and declarations of one's public entry into adult, Sundanese Muslim society. The attribution of certain behaviours and actions to the Karuhun or jurig jarian along with the will of establishing if a possession is real or pretended means discussing whether these behaviours are appropriate for a human being and which are their causes. From this perspective, the ma'alim is the spiritual and moral authority establishing the ontological statute of the spirit and thus giving a definitive, moral judgement about the spirit's social behaviour. An actual fixity of the taxonomies we have presented and a lack of negotiation would not allow such exchange and discussion.

\section{Conclusions}

As I have shown, possession, or in this case kasurupan, is a dense concept. It draws together the influence of different spirits and distinct relationships between one's body and mind, the mastery of the ma'alim and the agency of the supernatural beings. In terms of classification, I have also demonstrated that the possession experience often challenges taxonomical assumptions, defying the structures that attempt to circumscribe it (De Certeau, 1970). So, should this problematic prevent us from taking these classifications, and in general the possibility of any classification relative to the phenomenon of possession, into account? 
The anthropological tradition has shown how taxonomies and classifications of the natural and supernatural phenomena are ideological social structures that allow humans to understand and domesticate the world around them in order to act upon it (Douglas, 2013). From this perspective, anomalies and exceptions are experiences of the world that challenge these ideal, speculative taxonomies based on an empiric experience of the world (Valeri, 1999). In réak spirits' taxonomies of the Karuhun and jurig jarian are ideal categories. Theoretical poles between which anomalous and ambiguous concrete experiences of possession happen.

Yet, in this classificatory vagueness - opposed to a rather operational precision - a certain ambivalence is possible, that the two binary, strict definitions of Karuhun and jurig jarian would not allow. The dynamism (vigor, energy, tonicity) and fecundity of possession as a transformative social process is possible precisely thanks to a negotiation of this ambivalence, which in turn is possible because the experience of possession is ambiguous and not transparent.

As Boddy has pointed out (Boddy, 2010, p. 123), the functioning of possession at least partially relies on its provocative ambiguity. Ambivalence is the trait of possession that makes its narrative, communicative features rich and dense (Beneduce, 2002). Of course we should not refuse Cohen's innovative position for which an adequate study of the human mind's cognitive structure along with a study regarding global representations and perceptions of the possession experience may help in a cross-cultural, comparative study of the phenomenon as a pan-human occurrence (2008). Nonetheless, especially on a local level, accepting theoretical taxonomies and classifications like apodictic truths without enquiring their anomalies, fundamentally means both accepting approximate (even if indigenous) ideological categories and overlooking what gives meaning and importance to the experience itself. In this sense, taxonomies and categories should be regarded as valid and informative analytical constructs that have nonetheless to be questioned and deconstructed by the anthropologist. Only this way are we able to consider purely theoretical, ideological classifications in a way that is able to go beyond them, unearthing more incisive and relevant information about what possession really is for the subjects that experience it, how it works for them and what it produces in the communities where it is present.

\section{References}

Acciaioli, G. (2016). Culture as art: from practice to spectacle in Indonesia. In J. C. H. Lee \& M. Ferrarese (Eds.), Punks, monks and politics: Authenticity in Thailand, Indonesia and Malaysia (pp. 145-164). Rowman \& Littlefield.

Azzaroni, G. (1994). Teatro e società a Bali. CLUEB.

Beneduce, R. (2002). Trance e possessione in Africa. Bollati Boringhieri.

Boddy, J. (1994). Spirit possession revisited: Beyond instrumentality. Annual Review of Anthropology, 23, 407-434. https://doi.org/10.1146/annurev.an.23.100194.002203

Boddy, J. (2010). The work of Zâr: Women and spirit possession in northern Sudan. In J. Quack, J. Weinhold \& W. S. Sax (Eds.), The problem of ritual efficacy (pp. 113-149). Oxford University Press.

Bourguignon, E. (1976). Possession. Chandler \& Sharp Publishers.

Christensen, P. (2014). Modernity and spirit possession in Java: Horse dance and its contested magic. In V. Gottowik (Ed.), Dynamics of religion in Southeast Asia: Magic and modernity (pp. 91-110). Amsterdam University Press.

Cohen, E. (2008). What is spirit possession? Defining, comparing, and explaining two possession forms. Ethnos, 73(1), 101-126. https://doi.org/10.1080/00141840801927558

De Certeau, M. (1970). La possession de Loudun. Gallimard.

Deren, M. (1953). Divine horsemen: The living Gods of Haiti. Thames and Hudson.

Douglas, M. (2013). The Lele of the Kasai. Routledge.

Foley, K. (1990). My bodies: The performer in West Java. TDR, 34(2), 62-80. https://doi.org/10.2307/1146027

Geertz, C. (1976). The religion of Java. University of Chicago press.

Kartomi, M. J. (1973). Music and trance in central Java. Ethnomusicology, 17(2), 163-208. https://doi.org/10.2307/849881

Kartomi, M. J. (1976). Performance, music and meaning of Réyog Ponorogo. Indonesia, 22, 84-130. https://doi.org/10.2307/3350979

Kasmana, K., Setiawan S., Iwan G. \& Hafiz A. A. (2018). The belief in the existence of supernatural beings in the community of Moslem Sundanese. Journal of Arts and Humanities, 7(4), 11-21. https://doi.org/10.18533/journal.v7i4.1375

Mauricio, D. E. (2002). Jaranan of east Java: An ancient tradition in modern times. University of Hawaii. 
Monteanni, L. (2018). L'intrattenimento Sacro: Per un'analisi della danza sundanese del cavallo. [Unpublished master's thesis]. University of Bologna.

Monteanni, L. (2020). Il réak di Bandung tra rituale cerimoniale e intrattenimento popolare: Una tradizione contemporanea sundanese. Antropologia e Teatro. Rivista di Studi, 12, 29-41. https://doi.org/10.6092/issn.2039-2281/10883

Rapoport, E. (2018). Jathilan horse dance: Spirit possession beliefs and practices in the present-day Java. IKAT: The Indonesian Journal of Southeast Asian Studies, 2(1), 1-17. https://doi.org/10.22146/ikat.v2i1.37389

Talamonti, A. (2005). La carne convulsiva. Etnografia dell'esorcismo. Liguori.

Valeri, V. (1999). Uno spazio tra sé e sé. L’antropologia come ricerca del soggetto. Donzelli.

Van Groenendael, C. (2008). Jaranan: The horse dance and trance in East Java. KITLV press. 